\title{
Maltrato infantil: una mirada al interior de la familia en tiempos de confinamiento social
}

Jesús Morales (iD) https://orcid.org/0000-0001-8533-3442

Con la aparición del Covid-19 las relaciones sociales sufrieron un vuelco significativo en todas sus dimensiones. Como resultado del caos y la incertidumbre provocados por la pandemia, se han tomado a nivel mundial un cúmulo de medidas preventivas en un intento por mitigar los efectos de una enfermedad mortal con implicaciones multifactoriales en el funcionamiento individual y social. Esto sin lugar a duda constituyó una estrategia paliativa para frenar la tasa de contagio que experimentan la mayoría de los países. Sin embargo, la tensión sufrida por los organismos gubernamentales focalizados en resolver el problema de salud, dejaron a un lado los efectos colaterales del confinamiento social, que sometió a la población a convivir periodos prolongados y modificar los patrones de convivencia, condiciones que aceleraron la aparición de conductas violentas, situaciones de estrés, agresión física, maltrato psicológico y emocional, así como abusos sexuales infantiles. En tal sentido y con el propósito de mostrar los efectos del confinamiento social, se propone una revisión documental que deja ver el incremento alarmante que ha sufrido el maltrato infantil a nivel mundial.

Para ello se tomaron reportes periodísticos internacionales, los cuales aportan indicadores de riesgo que apuntan hacia un estado de emergencia infantil como resultado de la pandemia del Covid-19. Según la UNICEF [1] "aproximadamente seis de cada diez niños han experimentado alguna medida de disciplinaria violenta en sus hogares" (p.2). Un recuento del maltrato infantil desde el 2017, indica que cerca de 40.000 niños fueron víctimas de homicidio. Los reportes del año 2018 refieren a un ascenso leve en las cifras de muertes en niños, mientras que en el 2019 solo en México por tomar un referente significativo, de los "39.8 millones de niños y adolescentes, $63 \%$ de los menores entre 1 y 14 años han sufrido algún tipo de violencia en el hogar y a diario se registran 4 homicidios de niños, niñas y adolescentes" [2]. En el 2020 las estimaciones indican que un poco más de la mitad de los niños a nivel mundial han sido cometidos a "violencia física, sexual o psicológica, sufriendo lesiones, discapacidades y muerte" [4]. Para World Visión el panorama mundial es bastante abrumador, pues las estadísticas indican que la prevalencia mensual en lo que a maltrato infantil se refiere va en ascenso, discriminándose de la siguiente manera "América Latina 14.607.329, América del Norte 10.048.608, Oceanía 160.049, Europa 3.798.000, Asia 17.889.193 y África 57.440.932, para un total de 264.694.111" (p.11).

Si realizamos un paneo general sobre las consecuencias del confinamiento social, surgen como aspectos preponderantes, la vulnerabilidad que sufre la población infantil y la familia en general. Irónicamente, el hogar se ha convertido en un espacio inseguro, en el que como lo indica World Visión [3] "millones de niños en el mundo sufren un riesgo de violencia emocional, física y sexual; sus cuidadores asustados y ansiosos por la amenaza del virus y la desaceleración económica resultante, pueden arremeter contra los más cercanos a ellos" (p.4). La tensión y el desequilibrio emocional se han convertido en detonantes de la violencia doméstica. Este reporte confirma que el maltrato infantil durante el 2020 ascendió de un 20\% a un $32 \%$, cifras que se traducen en que cerca de unos 85 millones de niños a nivel mundial están expuestos a abusos emocionales, físicos, morales, psicológicos y sexuales.

${ }^{1}$ Universidad de Los Andes, Docente del Departamento de Orientación y Psicología General, Mérida 5101, Mérida, Venezuela. Correspondencia para: J Morales. E-mail:<lectoescrituraula@gmail.com/jmoralescarrero@yahoo.com> .

Como citar este artigo / How to cite this article

Morales J. Maltrato infantil. Una mirada al interior de la familia en tiempos de confinamiento social. InterAm J Med Health 2021;4:e202101012. https://doi.org/10.31005/iajmh.v4i.17 
Esto según la Organización de Naciones Unidas [4], significa que parte de la población vulnerable a nivel mundial está representada por niños y adolescentes, motivado entre otras razones, por la suspensión de actividades educativas, cuya incidencia negativa alcanzó a poco más de un 1500 millones de estudiantes, a los que se ha sometido a una estadía prolongada en hogares que experimentan elevados niveles de estrés, frustración, ansiedad, ira y problemas de hacinamiento, factores de riesgo a los que se le atribuye "mayores probabilidades de que los niños presencien o padezcan situaciones de abusos físicos, psicológicos y sexuales en el hogar, especialmente los niños que ya viven en contextos familiares disfuncionales o violento". Zmey [5] añade que el Fondo de Naciones Unidas para la Infancia, indica que "1800 millones de niños se encuentran desprotegidos y sin una instancia a la cual recurrir en caso de violencia y otros abusos". Esto explica en parte el rol importante que juegan tanto docentes, psicólogos y trabajadores sociales, en la mitigación y tratamiento de situaciones asociadas con la vulneración a la integridad física y emocional del infante.

La autora citando a la UNICEF, afirma que la violencia ascendió durante este año de manera alarmante, discriminándose de la siguiente forma "el $75 \%$ de los pequeños entre dos y cuatro años estaba sometido a métodos violentos de disciplina y una de cada tres adolescentes de 15 a 19 años había sido víctima de su pareja en algún momento". Según señala la Agencia PANA- Periodistas Amigos de la Niñez y Adolescencia, los maltratos giran en torno a "abusos físicos, sexuales, emocionales o abandono son algunas de las formas de maltrato que marcan la vida de millones de niños, niñas y adolescentes en todo el mundo". Esto permite inferir que el hogar ha dejado de ser un lugar seguro que posibilita el desarrollo psicosocial del niño, para convertirse en un factor de socialización disfuncional, incapaz de ofrecer las condiciones necesarias para el crecimiento integral.

Para Muñoz (2020) [6] América Latina es uno de los espacios del mundo con mayor índice de violencia. Los reportes indican que 99 millones (niños y adolescentes) se encuentran inmersos en maltrato físico y psicológico, la mitad de los menores con edad entre 2 y 4 años sufren castigos físicos severos. Peor aún "casi 80.000 niños y niñas mueren cada año como resultado del maltrato". El autor propone que las víctimas de violencia padecen de lo que denomina "trauma complejo", como resultado del sometimiento prolongado y sistemático del niño a diversos tipos de maltrato, cuyas implicaciones se extienden durante la infancia, la adolescencia y la adultez. Además, agrega que la reducción en la tasa de violencia de $51 \%$ a $20 \%$ se debe entre otras razones, a la interrupción de reportes realizados por trabajadores sociales, docentes y psicólogos, condición que ha imposibilitado la identificación de cifras reales que permitan realizar proyecciones sobre los giros de la violencia en esta población vulnerable.

En Venezuela, los casos de maltrato infantil se presentaron entre mayo y agosto, meses en los que seis niños fueron golpeados por sus padres y cuidadores hasta el punto de provocarles lesiones fatales que motivaron su muerte. A esto se suma el asesinato de una niña de cuatro años, a la que su padrastro le propinó una golpiza, convirtiéndose en uno de los casos más alarmantes a nivel nacional. La autora refiriéndose a los datos aportados por el Observatorio Venezolano de Violencia, indica que el 2019 fue uno de los años más violentos para Venezuela, pues la crisis social, la migración masiva, los elevados índices inflacionarios y la pobreza se han convertido en factores de riesgo; este año "arrojó 1.120 fallecidos, de los cuales 559 (49,9\%) fueron menores de 12 años de edad". Por lo general, el modus operandi de los victimarios fue la golpiza y el maltrato sistemático que derivó en lesiones irreversibles que ocasionaron la muerte, caso de seis niños menores de cinco años en diversos estados del país. Es preciso indicar que los sujetos implicados en homicidios a menores de edad, fueron personas cercanas (padres, abuelastros, padrastros, otros miembros de la familia y cuidadores).

La autora detalla otros casos de violencia infantil que terminaron con la muerte de las víctimas, entre los que se precisan: la muerte de un niño de cuatro años por parte de su madrastra, quien lo golpeó hasta desprenderle sus órganos vitales y ocasionarle hemorragias internas; un bebé de 18 meses falleció como resultado de fracturas múltiples en varias parte del cuerpo; caso semejante, un bebé de un mes de nacido falleció como resultado de golpes presentados en $50 \%$ de su cuerpo. Mireles (2020) [6] refiere que en México los casos de violencia contra niños involucran maltratos físicos y abusos sexuales propinados a infantes, así como el uso de torturas por parte de miembros de la familia. Las cifras indican que los entre los meses de mayo y junio, las denuncias por violencia infantil aumentaron un 17\% pasando de 16,060 a 18.884 .

Según Watch (2020) [7], las implicaciones del confinamiento social han puesto en riesgo a la niñez y la familia en general, pues las tensiones y los elevados niveles de ansiedad no solo se convirtieron en 
detonantes del maltrato a niños sino en impulsores de la disfuncionalidad. Este reporte atribuye al cierre de las escuelas la responsabilidad de la aparición de cuadros de depresión, agresión y estrés en infantes, a quienes se les ha obligado compartir más tiempo en escenarios familiares desintegrados o sometidos al cuidado de extraños, lo que acentúa las probabilidades de abuso sexual y psicológico. A esto es posible agregar otros abusos a los que niños y adolescentes son sometidos, entre los que se identifican: el trabajo infantil que alcanza "los 152 millones antes de la pandemia del COVID-19, de los cuales 73 millones realizaban trabajos peligrosos; a ello se une: la explotación sexual, la obligación a mendingar y vender productos en las calles para subsistir".

Lo anterior es igualmente compartido por Save the Children [8], al afirmar que las relaciones de convivencia al interior de la familia se han agravado, entre otras razones, por el maltrato sistemático que experimentan a diario los niños como resultado del estrés psicosocial al cual se le atribuye la generación de abusos emocionales y el incremento de la frustración. Como consecuencia, es predecible indicar que los traumas y las lesiones que a diario enfrentan los infantes repercutirán en su desarrollo socio-afectivo y psicológico, imposibilitando la convivencia y el establecimiento de vínculos empáticos y altruistas que impulsen su bienestar integral. Al respecto la Organización Mundial de la Salud [4], plantea que el confinamiento ha dejado en un profundo estado de indefensión a niños y adolescentes que ya venían sufriendo de algún tipo de maltrato, pues las nuevas rutinas y la crisis exacerbaron la vulnerabilidad de esta población, cercenándoseles el derecho a disfrutar de un clima psicológico y socialmente saludable, que impulse su potencial y fortalezca el desarrollo positivo de la personalidad (Lewchuk, 2020) [3].

\section{Indicadores de maltrato infantil}

Identificar algunos rasgos característicos del maltrato en niños y adolescentes, permite que tanto docentes, psicólogos y trabajadores sociales intervengan para mitigar sus implicaciones psicológicas, emocionales, sociales y morales. En niños son frecuentes las manifestaciones de tensión, frustración y aislamiento, así como emociones negativas como la ira, intolerancia y recurrentes cambios de humor. Como resultado del estrés, es posible que se tornen irascibles e irritables, y si el niño se encuentra sometido a castigos físicos es muy probable que se torne agresivo, inseguro y con una profunda sensación de desprotección que lo impulsa a experimentar sobresaltos, se torna retraído o introvertido, así como indiferente ante las responsabilidades o actividades que realizaba por placer. A estos rasgos se agrega el uso de insultos contra terceros, el sentimiento de culpa, de desvalorización y de baja estima.

Parte de los impactos que experimentan las víctimas de abuso infantil, tienen que ver con "la generación de un estado de confusión, ansiedad, desorganización y una gran pérdida de confianza en los demás" [6]. Para el autor, el denominado trauma complejo debe entenderse como el resultado del sometimiento sistemático y prolongado a maltratos en sus diversas tipificaciones, ocasionándoles a las víctimas dificultades alcanzar el desarrollo psicosocial positivo a lo largo del ciclo vital.

Con respecto al abuso sexual infantil se pueden precisar: el aislamiento social que posibilita al victimario para abusar de su víctima; pensamientos suicidas, depresión y ansiedad, ruptura de los canales comunicativos, rasgo que le imposibilita para expresar sus emociones, sentimientos y situaciones que le aquejan; la sospecha de chantaje acompañado de un voto de silencio que mantiene a la víctima sumida en el temor y en el miedo; retraimiento e inapetencia, conductas regresivas, terror a estar solo con algunos de sus familiares, así como dificultad para controlar los esfínteres, habiendo superado este proceso.

Sugerencias para intervenir/prevenir el maltrato infantil

Las acciones para prevenir y consolidar procesos de intervención efectivos, requiere comprender que el maltrato infantil obedece a un fenómeno multifactorial que exige el abordaje integral no solo del niño sino del contexto en el que este convive, es decir, a los miembros de la familia y demás actores. Algunas sugerencias desde la psicología pueden ser:

1. Educar a la familia para la convivencia, con especial énfasis en el manejo y gestión de las emociones. Esto permitirá que los niños y adolescentes tomen como referentes de protección, cobijo y seguridad a sus padres, quienes estarán en capacidad de estrechar lazos de ayuda.

2. Promover la comunicación, el diálogo abierto mediado por la confianza, de manera que el niño exprese sus sentimientos y emociones, procesos estratégicos que motivarán la búsqueda de soluciones conjuntas que impulsen la construcción de un clima psicológico positivo. 
3. Estrechar lazos de cooperación familiainstituciones educativas-organismos de protección, con el propósito de gestionar acciones conjuntas de seguimiento y acompañamiento a padres e hijos.

4. Fomentar el desarrollo de rutinas de trabajo, en las que se distribuyan las funciones según los roles y la capacidad de cada miembro de la familia. Esto atenuará los niveles de tensión, estrés y ansiedad, como factores de riesgo responsables de exacerbar el maltrato y abuso en sus diversas modalidades.

5. Acercar los mecanismos de protección a los niños y adolescentes, como medios que favorezcan la expresión de necesidades específicas. Ello implica la visita periódica a la familia y el monitoreo del funcionamiento familiar, con el propósito sugerir ajustes o modificación de conductas negativas que alteran el clima familiar, así como limitar el accionar del victimario.

\section{Promover campañas informativas contra el maltrato infantil, modalidades, implicaciones y consecuencias psicológicas, sociales, morales, físicas y emocionales, focalizando sobre las repercusiones penales y jurídicas para quienes lo perpetren. Esto pudiera convertirse en un poderoso mecanismo para disuadir e inmovilizar al victimario.}

7. Fortalecer la disciplina positiva y la participación de los padres en la consolidación de las tareas escolares. Ello sugiere fomentar el aprendizaje en familia, en el que sus miembros se integren sinérgicamente y desde el trabajo cooperativo en la resolución de actividades.

8. Promover el curriculum resiliente, en el que los procesos de enseñanza y aprendizaje privilegien el desarrollo de competencias emocionales y habilidades sociales, en función de las cuales enfrentar la crisis post-pandemia, resolver los conflictos pacíficamente mediante el diálogo respetuoso y la comunicación asertiva, y manejar la incertidumbre y el caos desde una actitud positiva. Según indica la UNICEF (2020b), es fundamental "la integración de contenidos relevantes en temáticas principales como salud mental y apoyo psicosocial, comunicación de riesgos y habilidades para la vida" (p.11).
9. Crear espacios educativos seguros que no se limiten al uso de las tecnologías de la comunicación e información, sino que favorezcan el contacto físico que posibiliten la expresión de empatía, apoyo, confidencialidad y protección contra el abuso en sus diversas modalidades. Esto coadyuvará en el abordaje de potenciales factores de riesgo que pudieran vulnerar la integridad de los niños y adolescentes.

10. Garantizar el acompañamiento psicosocial de calidad a la familia, a la comunidad y a la escuela, con el propósito de crear redes de apoyo en protección infantil.

11. Fomentar la educación para la convivencia social, abordando aspectos focales como: el fortalecimiento de las capacidades parentales, el desarrollo de la inteligencia emocional, comprensión de las normas que definen la construcción de lazos socio-afectivos positivos, y la adopción de un pensamiento flexible para modificar patrones de comportamiento nocivos que atentan contra la consolidación de un clima psicosocial positivo.

12. Integrar a la sociedad civil, su capital social y su liderazgo, como requerimientos fundamentales para la construcción redes de seguimiento, monitoreo, acompañamiento, asesoramiento y difusión de derechos y mecanismos de protección infantil.

13. Organizar actividades recreativas y de ocio, que potencien la integración familiar. Esto sugiere formulación de planes que involucren dinámicas asociadas con el juego de roles, la negociación y la resolución pacífica de conflictos, estrategias de relajación, las bondades del trabajo cooperativo, las simulaciones y el uso de la dramatización, como experiencias en la que cada miembro de la familia identifique-exprese las emociones positivas y negativas.

14. Fomentar prácticas positivas de crianza, en los que se fortalezca el uso del lenguaje positivo y el establecimiento de responsabilidades, así como la definición de límites de actuación con el propósito de evitar la transgresión del espacio del otro. 


\section{¿Qué hacer frente al maltrato infantil?}

La actuación del Estado a través de la construcción de políticas públicas con enfoque en la atención de la población infantil constituye una alternativa oportuna más no suficiente. Esto indica que, la minimización de la tasa de maltrato infantil en sus diversas modalidades, requiere la unificación de esfuerzos provenientes de la sociedad civil, instituciones educativas, cuerpos colegiados (psicólogos, sociólogos, educadores, criminólogos, trabajadores sociales) y la familia, con el propósito de crear redes de apoyo, monitoreo y asesoramiento sistemático, que permita precisar potenciales factores de riesgo que vulneren el bienestar integral de niños y adolescentes. Ello sugiere, educar a la sociedad para que asuma su rol protagónico como agente formador de ciudadanos, en quienes recae la responsabilidad de crear un clima psicológico positivo que garantice la calidad de vida y el desarrollo humano integral a lo largo del ciclo vital. A esto se agrega, la necesidad de consolidar instituciones sólidas cuya actuación eficiente imposibilite la reproducción de conductas violentas contra la familia $y$, de este modo recuperar la confianza en la denuncia como mecanismo para limitar el proceder del victimario.

En síntesis, la aparición del Covid-19 y las subsecuentes medidas de confinamiento social, han posibilitado la identificación de otros problemas sociales con impacto negativo igual o mayor, entre los que se precisan: el maltrato infantil, el abuso sexual, el uso de castigos severos y la violencia sistemática que padecen niños y niñas a nivel mundial. Frente a este panorama, se hace perentorio fortalecer los sistemas de protección y motivar la creación de mecanismos de ayuda de amplio alcance, con la capacidad de atender y prevenir los efectos de la violencia infantil.

\section{REFERENCIAS}

1. UNICEF. Protección de la niñez ante la violencia. Respuestas durante y después de COVID-19, 2020 [citado 2020 Jun 22. Disponível em: <https://www.unicef.org/ mexico/media/3506/file/Nota\%20t\%C3\%A9cnica:\%20 Protecci\%C\%B3n\%20de\%20la\%20ni\%C3\%B1ez\%20 ante $\% 201$ la $\% 20$ violencia $\% 20 . p d f>$.

2. Mireles A. Confinados con su agresor: por qué el COVID-19 recrudeció la violencia familiar en México, 2020 [citado 2020 Jun 22. Disponível em: <https://www. infobae.com/america/mexico/2020/07/22/confinados-con- su-agresor-por-que-el-covid-19-recrudecio-la-violenciafamiliar-en-mexico/>.

3. World Vision. Repercusiones del Covid-19, 2020 [citado 2020 Jun 22. Disponível em: <https://www.wvi.org/sites/ default/files/2020-06/COVID-19\%20aftershocks SP.pdf>.

4. Organización Mundial de la Salud. Los organismos advierten de que los países no han logrado prevenir la violencia contra los niños, 2020 [citado 2020 Jun 18]. Disponível em: <https://www.who.int/es/news/item/1806-2020-countries-failing-to-prevent-violence-againstchildren-agencies-warn>.

5. Zmey P. La irrupción del COVID-19 ha dejado a los niños sin protección frente a la violencia, 2020 [citado 2020 Ago 18]. Disponível em: <https://news.un.org/es/ story/2020/08/1479062>.

6. Muñoz, P. (26-10-20). Alertas para detectar y prevenir el maltrato infantil, 2020 [citado 2020 Out 26]. Disponível em: <https://blogs.iadb.org/desarrollo-infantil/es/maltratoinfantil/s.

7. Human Rights Watch. (2020). Devastador impacto del COVID-19 para niños y niñas, 2020 [citado 2020 Jun 22. Disponível em: <https://www.hrw.org/es/ news/2020/04/09/devastador-impacto-del-covid-19-paraninos-y-ninas\#>.

8. Save the Children. (25-04-20). El maltrato infantil también es un virus que se agrava con la pandemia COVID 19. http://pasc-lac.org/2020/04/24/el-maltrato-infantiltambien-es-un-virus-que-se-agrava-con-la-pandemiacovid-19-dia-internacional-de-la-lucha-contra-el-maltratoinfantil/ 